\section{Atmospheric Concentrations and Deposition of Trichloroacetic Acid in Scotland: Results from a 2-Year Sampling Campaign}

\author{
M. R. HEAL, $*,+N . M . R E E V E S,+A N D$ \\ J. N. CAPE‡
}

School of Chemistry, University of Edinburgh,

West Mains Road, Edinburgh, EH9 3JJ U.K., and

Centre for Ecology and Hydrology (Edinburgh), Bush Estate,

Penicuik, Midlothian, EH26 0QB U.K.

The first long-term concurrent measurements of trichloroacetic acid (TCA) in rainwater, in cloudwater, and in air (both gas and particle phase) are reported. Measurements were made weekly between J une 1998 and A pril 2000 at a rural forested upland site in SE Scotland. Rainwater TCA concentration did not differ significantly between two elevations (602 and $275 \mathrm{~m}$ asl), with precipitation-weighted mean values of 0.77 and $0.70 \mu \mathrm{g} \mathrm{L}^{-1}$, respectively $(n>$ 75). The precipitation-weighted mean concentration of TCA in cloudwater at the highest elevation was $0.92 \mu \mathrm{g} \mathrm{L}-1$, yielding an average cloudwater enrichment factor of 1.2, considerably lower than for other inorganic ions measured. Rainwater and cloudwater TCA concentrations did not vary systematically with season. Since wet precipitation depth also did not vary systematically with season, the wet deposition fluxes of TCA were likewise invariant (annual fluxes at the highest elevation of 880 and $130 \mu \mathrm{g} \mathrm{m}^{-2}$, respectively, for rain and cloud interception to spruce forest). Weekly integrated concentrations of TCA in air (gas and particle) were very low (median $25 \mathrm{pg} \mathrm{m}^{-3}$, range $<$ LOD$110 \mathrm{pg} \mathrm{m}^{-3}$ ). The estimated upper limit for annual dry deposition of TCA at this site was $\sim 20 \mu \mathrm{g} \mathrm{m}^{-2}$, assuming a deposition velocity of $2 \mathrm{~cm} \mathrm{~s}^{-1}$. Concentrations of TCA in air correlated reasonably strongly w ith concentrations in rainwater, with a partition ratio approximately equal to the Henry's law coefficient. On average, only about $23 \%$ of TCA measured in Edinburgh air was associated with the particle phase. These measurements are consistent with the observed high scavenging ratio of TCA (ratio of concentration in air to concentration in rainwater). Overall, these data confirm that the atmosphere is an important source of TCA to the environment and that precipitation is the dominant transfer mechanism. In line with previous work, the atmospheric deposition flux is greater than expected from the current understanding of atmospheric production of TCA from anthropogenic precursors. It is suggested that aqueous-phase processes could lead to greater

*Corresponding author telephone: +44 (0)131 650 4764; fax: +44 (0)131 650 4743; e-mail: m.heal@ed.ac.uk.

University of Edinburgh.

* Centre for Ecology and Hydrology (Edinburgh). atmospheric conversion of chlorinated solvent precursors to TCA than is currently accepted.

\section{Introduction}

Quantification of the concentrations and fluxes of trichloroacetic acid (TCA) in the environment is required as part of the environmental impact assessment imposed by regulatory authorities on themanufacturers of chlorine-containing solvents such as perchloroethene and trichloroethane. The concern is that reactions of some chlorinated solvents in the atmosphere constitute a source of TCA to the environment. TCA has known phytotoxic properties $(1,2)$. Although TCA is undoubtedly present in tree foliage (3), the evidence for effects on trees at environmental concentrations is equivocal $(4,5)$.

Since TCA is highly soluble in water $\left(1200 \mathrm{~g} \mathrm{~L}^{-1}\right)(6)$ and has a large Henry's law coefficient of $7.4 \times 10^{4} \mathrm{M}^{\mathrm{atm}}{ }^{-1}$ at $298 \mathrm{~K}(7)$, TCA present in the hydrosphere and biosphere, from whatever source, will not partition into the atmosphere to any extent. Therefore, atmospheric deposition of TCA is assumed to represent a source of "new" TCA to the environment. The issue is the extent to which putative industrial routes are responsiblefor the observed atmospheric flux of this new TCA.

Furthermore, therearewidespread suggestions that forests subject to prolonged contact with advective clouds (as are most upland forests in Europe) are exposed to higher concentrations of pollutants. There has only been one previously reported study of TCA in fogwater (8) in which an average fog/ rain ratio of 4.4 for TCA was measured. This is of particular concern given the relatively high mobility of TCA into and through the tree system.

In this study, we report the first measurements of TCA in rain, cloud, and air simultaneously for samples collected weekly for a period of almost $2 \mathrm{yr}$ at a site in SE Scotland. These are the first measurements for the U.K. In particular, we report the first measurements to apportion TCA in air between gas and particle phases. The concentration of TCA in rainwater was measured at two elevations, allowing evaluation of the effect of orography on TCA fluxto theforest. Some 50-80 measurements of TCA were made for each parameter.

\section{Experimental Section}

Sampling. Samples were collected at Glentress Forest $\left(55^{\circ} 40^{\prime}\right.$ $\mathrm{N}, 3^{\circ} 10^{\prime} \mathrm{W}$ ), an upland forest site in the Borders Region of Scotland, near Peebles, about $40 \mathrm{~km}$ south of Edinburgh. Theforest is a mixed plantation but dominated by Sitka spruce (Picea sitchensis) planted in the 1960s. Thesurrounding area is entirely rural. Precipitation measurements were made at two elevations: an upper site (Dunslair Heights), elevation $602 \mathrm{~m}$ asl, situated at the top of the hill in an open area of moorland between two tracts of forest, and a lower site (Venlaw), elevation $275 \mathrm{~m}$ asl, on the western flank (the direction of prevailing meteorology) in the middle of mixedage plantation blocks. The sites are operated by the NERC Centre for Ecology and Hydrology as part of a long-term investigation of the altitude dependence of the frequency of cloud and rain events and their chemical composition (9).

Weekly rainwater samples at Dunslair Heights and Venlaw were collected via a $200 \mathrm{~mm}$ diameter Pyrex glass funnel, set $1.5 \mathrm{~m}$ about ground level, draining into a polypropylene bottle. Weekly cloudwater was collected at Dunslair Heights 
TABLE 1. Results from Breakthrough Experiments for Sampling of TCA in Air ${ }^{\mathrm{a}}$

\begin{tabular}{ccccc} 
vol of air & \multicolumn{4}{c}{ TCA concn in air $\left(\mathbf{p g ~ m}^{-3}\right)$} \\
\cline { 2 - 5 } sampled $\left(\mathbf{m}^{\mathbf{3}}\right)$ & 1F & 1B & 2F & 2B \\
95 & 55 & nd & 30 & nd \\
115 & 27 & nd & 34 & nd \\
122 & 17 & nd & nd & nd \\
137 & 39 & nd & 20 & nd
\end{tabular}

${ }^{a}$ Filters designated $\mathrm{F}$ and $\mathrm{B}$ are front and back $\mathrm{Na}_{2} \mathrm{CO}_{3}$-impregnated filters in series to test for breakthrough. The designation 1 and 2 refers to duplicate pairs of filters sampling air in parallel. nd, not detected above blank.

using a passive "harp-wire" device, as described by Crossley et al. (10). The collector has the shape of an inverted cone with a solid polypropylene disk forming the base of the cone (i.e., the top of the collector) and polypropylene filaments ( $0.6 \mathrm{~mm}$ diameter) strung tautly around the sides of the cone. Cloud collection occurs by droplet impaction on the filaments. The apex of the cone sits inside a funnel that drains into a polypropylene bottle. Theentirecollector was covered by a 1.2 m diameter "lid" to exclude collection of rainfall, although rain droplets are also sampled for wind speeds $>5$ $\mathrm{m} \mathrm{s}^{-1}$. Deposition of cloudwater to the forest was estimated from the relative interception efficiencies of the collector, 0.29 (10), and forest, 0.06 (11), determined previously at the same site

Air sampling for TCA was conducted at Dunslair Heights using a novel technique devel oped for this work. The affinity of TCA for $\mathrm{Na}_{2} \mathrm{CO}_{3}$ was exploited by drawing air through a $\mathrm{Na}_{2} \mathrm{CO}_{3}$-impregnated $47 \mathrm{~mm}$ diameter open-face filter. Two filters weredeployed in parallel to provideduplicatesamples. This methodology quantifies total air TCA concentrations (i.e., gas phase and particle bound). Glass microfiber filters (Gelman A/C) were used as these were found to contain the lowest background levels of TCA and chloroform. Filterswere prepared by soaking in $0.1 \mathrm{M} \mathrm{Na}_{2} \mathrm{CO}_{3}$ solution and air-drying. Analysis blanks consisted of unexposed $\mathrm{Na}_{2} \mathrm{CO}_{3}$-impregnated filters. When not required, all filters and blanks were stored in sealed headspace vials previously heated to $100^{\circ} \mathrm{C}$ to drive offTCA and chloroform. Thefiltersand pump were mounted inside a plastic box $1.5 \mathrm{~m}$ abovethe ground, open at one end but protected by a set of polypropylene strings to remove any cloud droplets from the incoming air flow. Total flow rate through both filters was around $18 \mathrm{~L} \mathrm{~min}{ }^{-1}$, measured cumulatively with an in-line gas meter. Experiments with $\mathrm{Na}_{2} \mathrm{CO}_{3}$-impregnated filters in sequence established that there was no breakthrough from a single filter (Table 1) for a range of volumes of air sampled.

Air sampling was also undertaken at the School of Chemistry, located in the suburbs of the city of Edinburgh, in order both to providea comparison with therural site and to develop a method to distinguish between gas-phase and particle-bound TCA. Here each of the air inlets contained two filters in sequence: a nonimpregnated PTFE filter $(1 \mu \mathrm{m}$ pore size) in front to capture particles with the second $\mathrm{Na}_{2}-$ $\mathrm{CO}_{3}$-impregnated glass fiber filter behind to capture gasphase TCA.

Analysis. The TCA content of both water and filter samples was determined by thermal decarboxylation of TCA to chloroform $\left(\mathrm{CHCl}_{3}\right)$ and quantification of the latter by headspace gas chromatography with electron capture detection (GC-ECD), similar to the method of Plumacher and Renner (12). This is a straightforward method requiring no sample pretreatment. A sample of $5 \mathrm{~mL}$ of water was sealed in a $20-\mathrm{mL}$ volume headspace vial and heated at $100^{\circ} \mathrm{C}$ to convert TCA to $\mathrm{CHCl}_{3}$. The optimum decarboxylation time of $90 \mathrm{~min}$ was determined from a series of experiments with

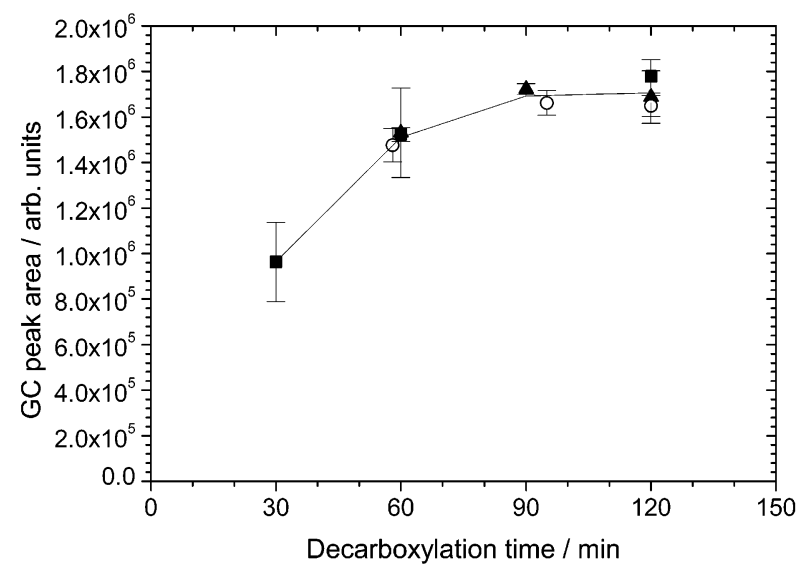

FIGURE 1. Determination of the optimum decarboxylation time at $100{ }^{\circ} \mathrm{C}$ for conversion of TCA to $\mathrm{CHCl}_{3}$ (the latter is detected by GC-ECD). The different symbols represent experiments conducted on three different occasions, each time with $5 \mathrm{~mL}$ of $5 \mu \mathrm{g} \mathrm{L}^{-1}$ TCA standard in the headspace vial. The error bars are SD of triplicate analyses for each experiment. The solid line is included to visualize the trend and shows that maximum decarboxylation is achieved within $90 \mathrm{~min}$.

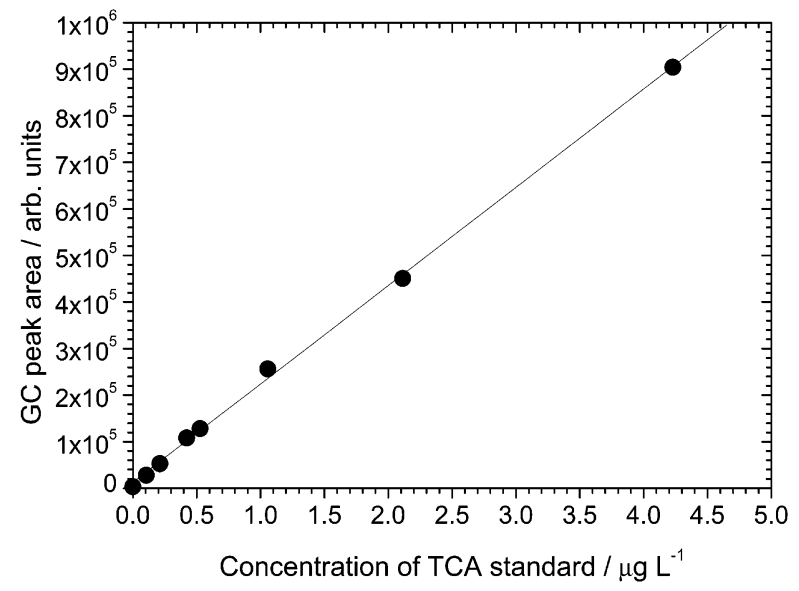

FIGURE 2. Example TCA standard calibration plot in the range of $0-4.3 \mu \mathrm{g} \mathrm{L}^{-1}$. In each case, $\mathrm{GC}$ area is corrected for background $\mathrm{CHCl}_{3}$ and TCA in the water by subtracting the peak area from a "blank" water sample also heated to $100{ }^{\circ} \mathrm{C}$.

a $5 \mu \mathrm{gL}^{-1}$ standard, as shown in Figure 1. The vials were then equilibrated at $60^{\circ} \mathrm{C}$ for $60 \mathrm{~min}$, and an aliquot of headspace was transferred to a Perkin-Elmer Autosystem GC by a PE HS-40 headspace autosampler. Chromatography for $\mathrm{CHCl}_{3}$ was performed isothermally at $50^{\circ} \mathrm{C}$ on a DB- 5 column (injector temperature $200^{\circ} \mathrm{C}$, detector temperature $375^{\circ} \mathrm{C}$ ). The presence of any background $\mathrm{CHCl}_{3}$ in the water sample, which would interfere with $\mathrm{CHCl}_{3}$ from TCA decarboxylation, was accounted for by subtracting the amount of $\mathrm{CHCl}_{3}$ determined in a parallel vial of $5 \mathrm{~mL}$ of sample equilibrated to $60^{\circ} \mathrm{C}$ only.

Rain and cloudwater samples were calibrated directly against a sequence of $5 \mathrm{~mL}$ of standard TCA solutions, ranging in concentration from 0.2 to $2 \mu \mathrm{g} \mathrm{L}^{-1}$ processed in exactly the same way. An example calibration plot demonstrating the linearity achievable for low concentration standards is shown in Figure 2. Direct calibration against TCA standard solutions rather than against $\mathrm{CHCl}_{3}$ solutions avoided any bias arising from incomplete decarboxylation of TCA to $\mathrm{CHCl}_{3}$. In fact, as shown in Figure 1, experiments indicated that decarboxylation was complete. Separate experiments also demonstrated stoichiometric decarboxylation of TCA to $\mathrm{CHCl}_{3}$; a direct comparison of TCA and $\mathrm{CHCl}_{3}$ solutions across the 
range of 30-210 $\mu \mathrm{g} \mathrm{L}^{-1} \mathrm{TCA}$ (or $\mathrm{CHCl}_{3}$ equivalent) gavelinear responses with identical slopes $( \pm 0.7 \%)$ and intercepts $( \pm 4 \%)$, well within the experimental uncertainties.

Every sample was analyzed in triplicate and was reanalyzed if triplicate RSD exceeded $40 \%$. Average triplicate RSD values for aqueous samples were around $10-17 \%$ (see Results). Thelimit of detection of this method was determined to be around $0.1 \mu \mathrm{g} \mathrm{L}^{-1}$.

Air sample filters were analyzed slightly differently. Each filter (sample or blank) was heated in an open vial for $45 \mathrm{~min}$ at $60^{\circ} \mathrm{C}$ to remove any background $\mathrm{CHCl}_{3}$. The vial was then capped, heated at $100^{\circ} \mathrm{C}$ to decarboxylateTCA, reequilibrated at $60^{\circ} \mathrm{C}$, and analyzed as above. Subtraction of the blank filter GC signal accounted for any TCA intrinsic to the filter or the $\mathrm{Na}_{2} \mathrm{CO}_{3}$ solution. External calibration was performed against GC signals from vials into which $200 \mu \mathrm{L}$ of TCA solutions of different concentration had been injected. Each filter could be analyzed only once, although the sampling setup yielded duplicate sample filters each week. Data presented are the means of these duplicates.

The decarboxylation analytical techniqueis indirect, and it was not possiblein this work to compare this methodology with an extraction and derivatization technique for TCA analysis. On the other hand, the decarboxylation technique does not require multistep extractions and analytical manipulations. While there remains the possibility that other materials in the sample matrix might yield $\mathrm{CHCl}_{3}$ under the sample decarboxylation conditions, it seems unlikely for rainwater and air matrixes. Background $\mathrm{CHCl}_{3}$ blanks were al ways performed for every air filter and precipitation analysis.

\section{Results and Discussion}

Rain and Cloud. Figure 3 a shows the time-series of weekly depth of rain and cloud precipitation at Dunslair Heights for the period June 1998 to April 2000 inclusive. Cloudwater deposition to the forest canopy was derived as described in the Experimental Section. The corresponding time-series of TCA concentrations in weekly samples of cloudwater (from Dunslair Heights) and rainwater (from Dunslair Heights and Venlaw) are shown in Figure 3b. The weekly average TCA concentrations in air (total gas and particlephase) at Dunslair Heights and in the City of Edinburgh are shown in Figure $3 c$. A summary of median and range values of TCA concentrations are given in Table 2 . The table also indicates the mean and median \% RSD associated with each type of concentration measurement. For aqueous and air concentration measurements, average RSD values were in therange of 10$17 \%$ and $21-30 \%$, respectively. Analytical uncertainty was higher for air concentrations sinceonly duplicate, rather than triplicate, measurements were possible and because the concentrations were extremely low.

Figure $3 a$ shows that there is not a strong seasonal variation in rainfall at Dunslair Heights. Monthly rainfall can be as high in summer as in winter. This is typical of the maritime climate of the U.K. Appropriately scaling the total precipitation depths of this 23-month sampling campaign gives annual equivalent rainwater and cloudwater depths (to forest) at Dunslair Heights of 1150 and $139 \mathrm{~mm}$, respectively. Cloudwater therefore constituted $11 \%$ of the estimated total wet deposition to forest. These values are lower than the annual average rainwater and cloudwater depths of 1300 and $390 \mathrm{~mm}$, respectively, at the same site for the 10 years between 1987 and 1996 (9), indicating that the 1998-2000 measurements corresponded to a dryer than average period. In particular, there was substantially less cloudwater deposition than in the previous 10-yr period. Weekly cloudwater and rainwater depths are significantly correlated, although the correlation is not strong $(r=0.47)$. The 12-month equivalent rainfall at the lower elevation Venlaw site during the 23-month sampling period was 1016 $\mathrm{mm}$ or $89 \%$ of therainfall depth at the upper site. As expected, weekly rainfall correlated strongly between the sites ( $r=$ $0.81)$.

Figure $3 b$ shows no obvious seasonality in TCA concentration in rain and cloudwater. This is in agreement with the conclusion of McCulloch (3), who recently reviewed all relevant literature and suggested that there is not a strong seasonally dependent source of TCA in theatmosphere. Since TCA concentration and precipitation depth are both seasonally invariant, the wet deposition flux of TCA at this site is also invariant with season, as shown in Figure 4.

Figure $3 \mathrm{~b}$ and Table 2 also show that the concentration of TCA in rain did not differ significantly between the two elevations of Dunslair Heights and Venlaw. A pairwise plot of the data (Figure 5), although scattered, demonstrates significant correlation of rainwater concentration at the two sites ( $r=0.47, n=78$ ). The precipitation-weighted mean rainwaterTCA concentrationsatDunslair Heights and Venlaw (calculated as $\sum$ (concentration $\times$ depth)/ $\sum$ depth) were not significantly different at 0.77 and $0.70 \mu \mathrm{g} \mathrm{L}^{-1}$, respectively. This is consistent with TCA in rain being the consequence of a well-mixed process in the atmospheric boundary layer. There was no correlation between rainwater TCA concentration and weekly rainfall depth. This is in agreement with Reimann et al. (13), who did not observe any relationship of rainwater TCA concentration with volume of rain, duration of previous dry period, amount of 3-day antecedent rainfall, mean of 3-day antecedent temperature, or solar radiation. However, the data reported here are for integration of rainwater deposition during 1-week periods rather than individual rainfall events, and this will act to obscure evidence of "washout" effects. Berg et al. (14) also reported no obvious temporal and spatial patterns of TCA concentrations in rainfall in Switzerland.

In contrast to the lack of relationship between TCA concentration and precipitation depth for rainwater, there was a fairly strong inverse relationship between the two for cloudwater, as shown in Figure 6. Thus, instances of very high concentrations of TCA in cloudwater (reaching 7.1 $\mu \mathrm{g}$ $\mathrm{L}^{-1}$ in one sample, see Figure 3b) were offset by low precipitation volumes and did not significantly impact on thetime-series of cloudwater deposition flux (Figure 4). Over thewholestudy, the precipitation-weighted mean cloudwater TCA concentration at Dunslair Heights was $0.92 \mu \mathrm{g} \mathrm{L}^{-1}$, corresponding to an average weekly cloudwater concentration "enrichment" factor of 1.2 (range 0.44-10) as compared with the precipitation-weighted mean rainwater concentration of $0.77 \mu \mathrm{g} \mathrm{L}^{-1}$. Overall, the calculated 12-month equival ent wet deposition fluxes to forest of TCA via rain and cloud at Dunslair Heights are 884 and $128 \mu \mathrm{g} \mathrm{m}^{-2}$, respectively. Thereforeduring this measurement period, cloud contributed about $13 \%$ of total deposition of TCA, which isnotsignificantly different from the cloud hydrological input to the forest of $11 \%$.

In contrast, the median weekly cloudwater/rainwater concentration ratios of other inorganic ions measured at Dunslair Heights ranged from 5.3 for $\mathrm{K}^{+}$to $17 \mathrm{for} \mathrm{Cl}^{-}$(Table 3). There was no significant correlation of concentration of TCA with $\mathrm{Cl}^{-}$(taken to be an indicator of air masses with a marine origin) or with nonmarine $\mathrm{SO}_{4}{ }^{2-}$ (taken to be an indicator of air masses with significant anthropogenic input) in either rainwater or cloudwater. In the only previous study of TCA in fogwater (at an elevation of $776 \mathrm{~m}$ asl in Eastern Bavaria, Germany), Rompp et al. (8) reported no dependence of TCA concentration on fogwater volume and a median fog/rain concentration ratio of 4.4 .

Air. The concentrations of TCA in air at Dunslair Heights (Figure $3 \mathrm{c}$ and Table 2 ) are very low (median $25 \mathrm{pg} \mathrm{m}^{-3}$ ). In 52 weekly samples, the measured concentration did not exceed $110 \mathrm{pg} \mathrm{m}^{-3}$ and on several occasions was below the 

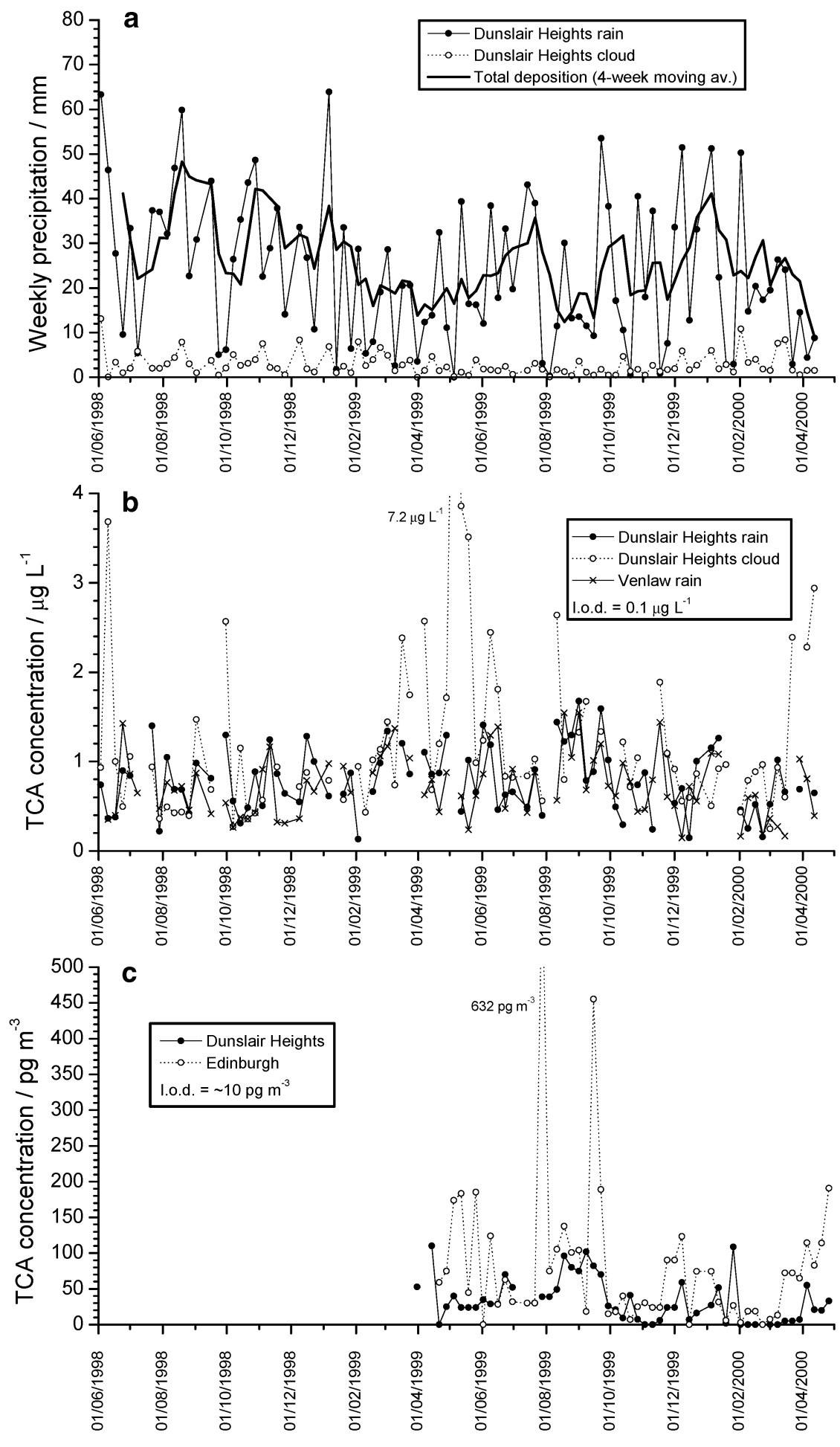

Sampling date

FIGURE 3. Time-series measurements from Glentress Forest and from Edinburgh, J une 1998-April 2000: (a) Weekly rainwater and cloudw ater precipitation depth at Dunslair Heights (Glentress Forest). The derivation of cloudw ater interception depth by the forest canopy is described in the text. (b) TCA concentrations in rainw ater and cloudwater from Dunslair Heights (602 $\mathrm{m}$ asl) and Venlaw (275 $\mathrm{m}$ asl), Glentress Forest. (c) Total air concentrations of TCA (gas and particle phases) at Dunslair Heights and in the city of Edinburgh. To aid clarity in the plots, error bars for individual data points are not show $n$. Relative standard deviations averaged around $10-17 \%$ for triplicate analyses of TCA in cloudwater and rainw ater and around $20-30 \%$ for duplicate analyses of gaseous, particle-bound, and total TCA in air (see also Table 2).

level of quantification value, $\sim 10 \mathrm{pg} \mathrm{m}^{-3}$. The median concentration of TCA measured concurrently in Edinburgh air, although about double the median air concentration measured at Dunslair Heights, was also generally very low
(Figure $3 c$ and Table 2). TCA in Edinburgh air was characterized by a couple of instances of weeks with concentrations of several hundreds of $\mathrm{pg} \mathrm{m}^{-3}$. The Edinburgh sampling site was the roof of the Chemistry Department in the middle of 
TABLE 2. Summary of 1-Week Average Wet Precipitation and Atmospheric (Total Gas and Particle Phase) Concentrations of TCA Measured at Glentress Forest and Edinburgh (V une 1998-April 2000) ${ }^{\text {a }}$

location

Glentress Forest, Dunslair Heights Glentress Forest, Dunslair Heights Glentress Forest, Venlaw

Glentress Forest, Dunslair Heights Edinburgh

n

mean

median

range

Wet Precipitation $\left(\mu \mathrm{g} \mathrm{L}^{-1}\right)$

$\begin{array}{lrlll}\text { Cloudwater } & 75 & 1.2(12 \%) & 0.93(10 \%) & 0.25-7.2 \\ \text { rainwater } & 78 & 0.80(17 \%) & 0.76(14 \%) & 0.13-1.7 \\ \text { rainwater } & 78 & 0.72(14 \%) & 0.68(13 \%) & 0.15-1.6 \\ & \text { Air }\left(\mathbf{p g ~ m}^{-3}\right) & & & \\ \text { total } & 52 & 33(30 \%) & 25(24 \%) & \mathrm{nq}-110 \\ \text { total } & 52 & 83 & 61 & \mathrm{nq}-632 \\ \text { gas phase } & 52 & 64(24 \%) & 38(24 \%) & \mathrm{nq}-484 \\ \text { particle phase } & 52 & 22(27 \%) & 11(21 \%) & \mathrm{nq}-184\end{array}$

a nq, not quantifiable (below blank). Values in parentheses are the mean and median relative standard deviations (RSD) obtained for triplicate analyses of wet precipitation samples and for duplicate analyses of air samples.

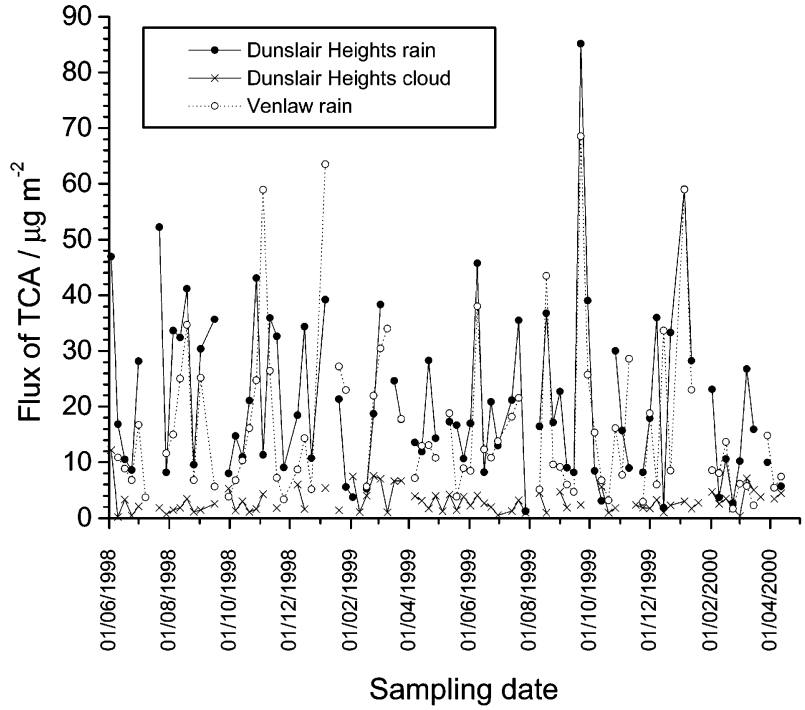

FIGURE 4. Time-series of weekly wet deposition flux of TCA in rain and cloud at the Dunslair Heights and Venlaw sampling sites in Glentress Forest, J une 1998-April 2000. To aid clarity, error bars for individual data points are not shown. How ever, given the uncertainties in analyses of TCA concentrations (Figure 3 and Table 2), relative standard deviations for deposition flux values will also average around $10-17 \%$.

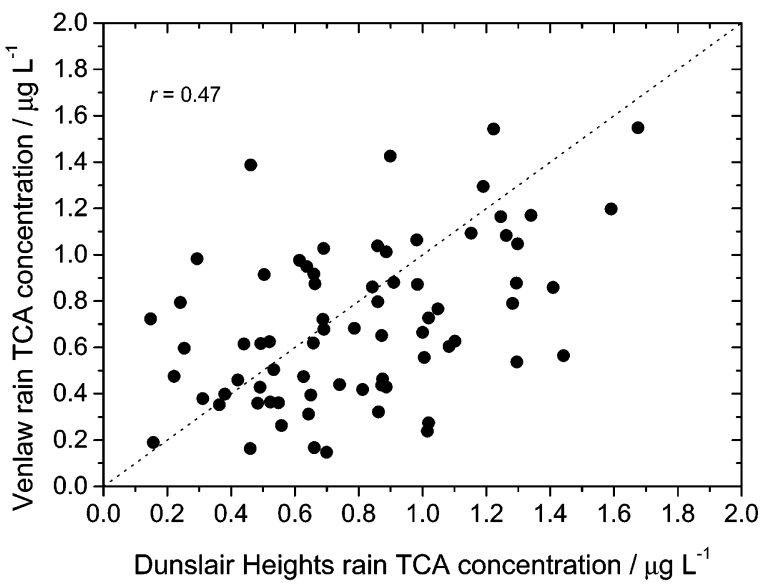

FIGURE 5. Relationship between TCA concentrations in weekly samples of rain at Dunslair Heights (602 $\mathrm{m}$ asl) and Venlaw (275 $\mathrm{m}$ asl), both sites at Glentress Forest.

the science area of Edinburgh University, so local sources of chlorinated solvents were likely. There is some hint of enhanced concentrations of TCA in air in thesummer months as compared with the winter months, but the trend is not

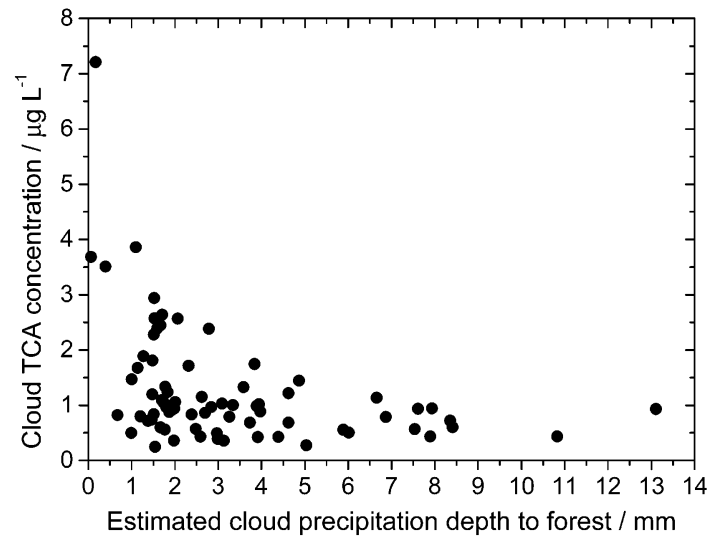

FIGURE 6. Relationship betw een estimated deposition depth and TCA concentration in w eekly samples of cloudw ater from Dunslair Heights, Glentress Forest.

TABLE 3. Cloudwater/Rainwater Concentration Ratios of TCA and Inorganic lons in Weekly Samples at Dunslair Heights (J une 1998-April 2000, $n=72$ )

\begin{tabular}{lccr} 
& \multicolumn{3}{c}{ cloudw ater/rainw ater concn ratio } \\
\cline { 2 - 4 } & median & $\min$ & $\max$ \\
$\mathrm{TCA}$ & 1.2 & 0.4 & 10 \\
$\mathrm{Na}^{+}$ & 11 & 1.7 & 73 \\
$\mathrm{~K}^{+}$ & 5.3 & 0.6 & 38 \\
$\mathrm{Ca}^{2+}$ & 8.9 & 1.1 & 89 \\
$\mathrm{Mg}^{2+}$ & 19 & 3.1 & 90 \\
$\mathrm{NO}_{3}{ }^{-}$ & 7.9 & 0.8 & 210 \\
$\mathrm{NH}_{4}{ }^{+}$ & 7.5 & 0.8 & 240 \\
$\mathrm{Cl}^{-}$ & 17 & 2.7 & 100 \\
$\mathrm{SO}_{4}{ }^{2-}$ & 8.3 & 2.8 & 53 \\
${ }^{a}$ Data are for nonmarine $\mathrm{SO}_{4}{ }^{2-}$. & & \\
\hline
\end{tabular}

strong and is not apparent in the longer time-series of concentrations of TCA in rain.

There are extremely few previous measurements of TCA in air and no published attempt to apportion between air and particulate-bound TCA. Frank et al. (15) report 12 measurements of TCA in urban air in Tübingen, Germany, ranging from 25 to $\sim 300 \mathrm{pg} \mathrm{m}^{-3}$. These workers used from two to four horizontal $\mathrm{Na}_{2} \mathrm{CO}_{3}$-coated glass denuders, so both air and a proportion of particulate TCA was collected. Values of TCA in air up to a few hundred $\mathrm{pg} \mathrm{m}^{-3}$ from isolated measurements in The Netherlands have also been reported (16)

The negligible TCA in air as compared with the atmospheric aqueous phase is expected from TCA's high water solubility. The relationship between weekly concentrations of TCA in rain and air at Dunslair Heights is shown in Figure 


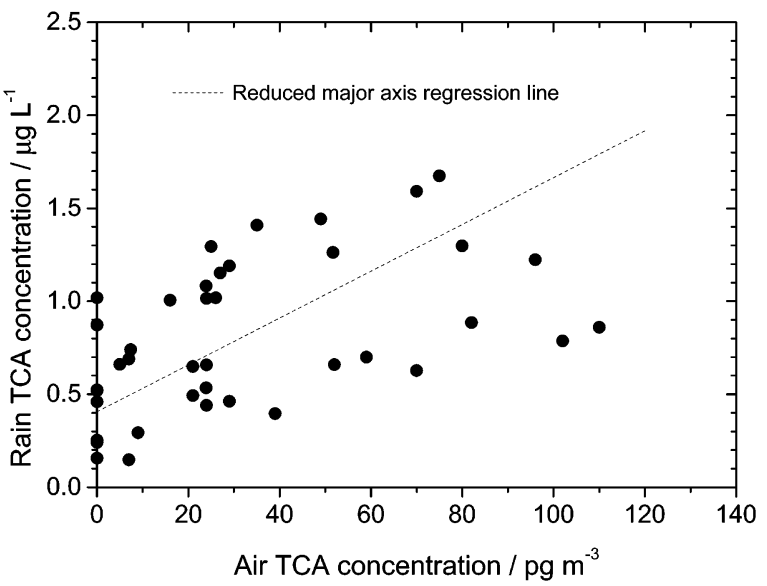

FIGURE 7. Relationship betw een w eekly average concentration of TCA in rain and air at Dunslair Heights, Glentress Forest. Air concentrations of less than $\sim 10 \mathrm{pg} \mathrm{m}^{-3}$ are probably below reliable level of quantification.

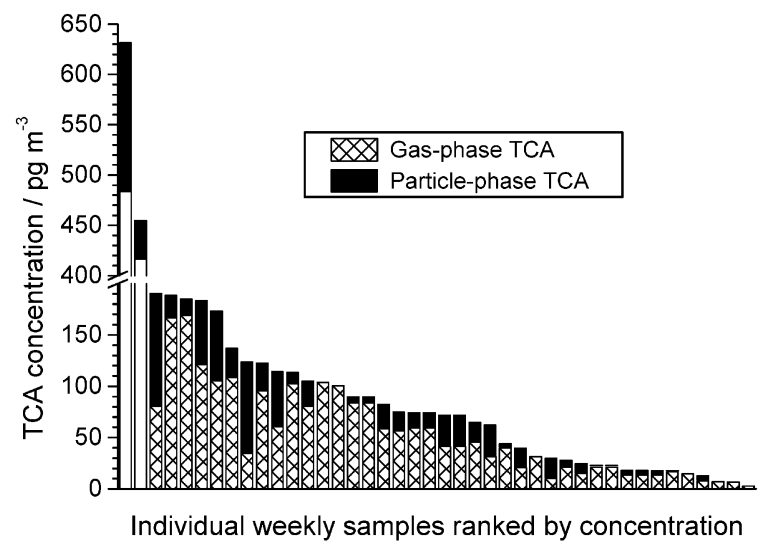

FIGURE 8. Contribution of gas-phase and particle-associated TCA to total concentration of TCA in air in Edinburgh. The method for discrimination is described in the text. Data are w eekly means and arranged in descending order of measured total air TCA concentration. Relative standard deviations of duplicate measurements of TCA in air averaged around $20-30 \%$ (see also Table 2).

7. The reasonably strong linear correlation between the two ( $r=0.48, n=39$ ) indicates that TCA behavior in the atmosphere at this site may be controlled by an equilibrium (Henry's law) partitioning. The gradient of Figure 7 is $\sim(1-2) \times 10^{-2} \mu \mathrm{g} \mathrm{L}^{-1} \mathrm{pg}^{-1} \mathrm{~m}^{3}$ which, with appropriate unit adjustment for $\mathrm{T} \sim 283 \mathrm{~K}$, corresponds to $\mathrm{H} \sim 6 \times 10^{5} \mathrm{M}$ atm $^{-1}$. The literature value for $\mathrm{H}$ at this temperature is $\sim 3$ $\times 10^{5} \mathrm{M} \mathrm{atm}^{-1}(7)$ and is strongly temperature dependent, although the high degree of TCA dissociation at likely rainwater $\mathrm{pH}$ values $\left(\mathrm{pK}_{a}\right.$ of TCA $\left.\sim 0.5-1\right)$ means that the effective $\mathrm{H}$ value for TCA will besomewhat greater. Although correlation between air and rain TCA concentrations are positive, there is an inverse trend between weekly air TCA concentration and TCA wet deposition flux, consistent with higher air concentrations being associated with drier periods. The data in Figure 7 yield a TCA scavenging ratio (expressed as the ratio of mass TCA in water per mass water to mass TCA in air per mass air) of approximately $2 \times 10^{4}$. This value is very much higher than thetypical scavenging ratio of $\sim 1000$ for sulfate (a hygroscopic fineaerosol) and likewise indicates that the majority of the TCA in the air is in the gas phase rather than in the particle phase.

The above discussion is supported by the direct measurement of TCA apportionment between gas and particle phases in Edinburgh air, shown in Figure 8. The average percent of particle-bound TCA across all weekly samples was
$23 \%$ ( $n=42$, range $0-82 \%$ ). Calculating average gas and particle-bound TCA concentrations over the whole period gave a similar proportion of $24 \%$ as particle bound. Similar behavior is assumed for the rural Glentress Forest site. The lack of association of TCA with particulate phase is predicted from thermodynamic modelsof gas/ particle partitioning onto aerosol by adsorption/ absorption. For example, Pankow (17) shows that gas/ particle partitioning is adequately described by the general relationship

$$
\log K_{p} \approx-\log p_{L}^{\circ}-8
$$

where $p_{L}$ is the vapor pressure (Torr) of the pure component, and $K_{p}=(F / T S P) / A$ is the gas-particle partitioning coefficient, with $F$ and $A$ as the concentrations $\left(\mathrm{ng} \mathrm{m}^{-3}\right)$ of the component in the particle and gas phases, respectively, and TSP as the concentration of total suspended particles $\left(\mu \mathrm{g} \mathrm{m}^{-3}\right)$. Using a $\mathrm{p}_{\perp}^{\circ}$ value of $\sim 20 \mathrm{~Pa}$ for TCA at $298 \mathrm{~K}(16)$, yields an F/A ratio less than $10^{-5}$ for any realistic value of atmospheric TSP concentration. However, in reality a proportion of atmospheric aerosol will consist of water, in which TCA will dissociate, and not strictly follow theapproach above.

In any event, the observed lack of TCA associated with airborne particlesisconsistent both with the high scavenging ratio between rain and air and the lack of significant enrichment of cloudwater relative to rainwater. The wet maritime climate experienced in Scotland probably ensures that TCA is washed out from the atmosphere before droplets can evaporate to leave particle-bound TCA. In fact, the generally equilibrium partitioning of TCA between gas and aqueous phases in the atmosphere may indicate TCA production within the aqueous phase and subsequent degassing.

Although a dry deposition vel ocity for TCA has never been measured, it is very unlikely to exceed an average value of $\sim 2 \mathrm{~cm} \mathrm{~s}^{-1}$ to the forest canopy at Dunslair Heights, assuming similar behavior to $\mathrm{HNO}_{3}$. Combining this with the average air TCA concentration of $\sim 30 \mathrm{pg} \mathrm{m}^{-3}$ yields an upper limit of $\sim 20 \mu \mathrm{g} \mathrm{m}^{-2}$ for annual dry deposition flux of TCA. This is negligible as compared with the annual wet deposition of $\sim 1000 \mu \mathrm{g} \mathrm{m}^{-2}$ TCA at this site. (The uncertainty in this deposition value will be dominated by analytical uncertainty in aqueous TCA concentration measurement, in particular for rain, which as discussed above was of the order of $\pm 15 \%$.)

Thefluxvalues show that the atmosphere is an important source of TCA to the environment and that precipitation is the dominant transfer mechanism to the biosphere. The atmospheric TCA deposition flux calculated for Scotland is larger than the range of estimates for Switzerland of $450 \mu \mathrm{g}$ $\mathrm{m}^{-2}$ (18), $150 \mu \mathrm{gm}^{-2}(13)$, and $360 \mu \mathrm{g} \mathrm{m}^{-2}$ (14) butcomparable with the below-canopy estimate of deposition of $\sim 700 \mu \mathrm{g}$ $\mathrm{m}^{-2}$ for forests in Germany and The Netherlands (19), particularly since none of these studies included the contribution of cloud deposition. However, despite the discrepancies, all these measurements of atmospheric fluxare greater than predicted from currently presumed TCA yield from emissions and atmospheric reactions of relevant chlorinated precursors (3). If the processes currently accepted asforming TCA from its precursors are correct, then the evidence presented here suggests an as yet unidentified additional source of TCA. However, heterogeneous processes in the aqueous phase have not been well-characterized, allowing the possibility that more TCA is formed from chlorinated solvents than previously proposed. Routes to TCA formation requirethat chloral $\left(\mathrm{CCl}_{3} \mathrm{CHO}\right)$ and/or trichloroacetyl chloride ( $\mathrm{TCAC}, \mathrm{CCl}_{3} \mathrm{CClO}$ ) transfer to the aqueous phase where they are oxidized. The lifetime of TCAC to photolysis is estimated to be $\sim 60 \mathrm{~d}(20)$, so aqueous removal will dominate its fate in the troposphere. The absorption cross-section of chloral 
has recently been remeasured (21), from which a photolytic lifetime in the troposphere of 5-10 h was derived, and assumed to dominate loss of chloral by aqueous-phase uptake. The photolysis rate coefficient was derived for midsummer at latitude $30^{\circ} \mathrm{N}$. So for the Scottish latitudes, an average lifetime to photolysis of $10-20 \mathrm{~h}$ is moreappropriate. Combined with the high wet precipitation frequency in Scotland, aqueous-phase processes for chloral may be considerably more important here than elsewhere in the world.

This work shows that TCA is not simplya Central European issue but that deposition fluxes to the maritime western seaboard of Europe are at least as important. These fluxes probably represent a Northern Hemisphere "background" flux and emphasize the need to understand the source of TCA in precipitation. It is possible to speculate that TCA in air arises from degassing from rain (i.e., there may exist an aqueous source of TCA involving a suitable precursor and appropriate aqueous phase chemistry (via $\mathrm{OH}$ or $\mathrm{Cl}$ radicals, and/or photolysis, and/or Fenton-type chemistry) not yet included in atmospheric sources of TCA). A suggestion that the sea may be a source of other precursors or of TCA is, at this point, entirely speculation.

\section{Acknowledgments}

N.M.R. thanks the U.K. Natural Environment Research Council and the Centre for Ecology and Hydrology for the award of a CASE studentship through the Environmental Diagnostics Programme. The assistance of staff at $\mathrm{CEH}$, Edinburgh, who operate and maintain the sampling site at Glentress Forest, is gratefully acknowledged. The EuroChlor organization contributed funding to purchase the HS-40 headspace sampler.

\section{Literature Cited}

(1) Lockhart, J. A. R.; Samuel, A.; Greaves, M. P. Weed Control Handbook, Vol. 1, Principles; Hance, R. J., Holly, K., Eds.; Blackwell: Oxford, 1990; Chapter 2.

(2) Crafts, A. S. The Chemistry and Mode of Action of Herbicides; Wiley-Interscience: New York, 1961.
(3) McCulloch, A. Chemosphere 2002, 47, 667-686.

(4) Frank, H.; Scholl, H.; Sutinen, S.; Norokorpi, Y. Ann. Bot. Fenn. 1992, 29, 263-267.

(5) Juuti, S.; Norokorpi, Y.; Helle, T.; Ruuskanen, J. Sci. Total Environ. 1996, 180, 117-124.

(6) Morris, E. D.; Bost, J. C. Kirk-Othmer Encyclopaedia of Chemical Technology, 4th ed.; Kroschwitz, J. I., Ed.; Wiley: New York, 1991; Vol. 1.

(7) Bowden, D. J.; Clegg, S. L.; Brimblecombe, P. Water Air Soil Pollut. 1998, 101, 197-215.

(8) Römpp, A.; Klemm, O.; Fricke, W.; Frank, H. Environ. Sci. Technol. 2001, 35, 1294-1298.

(9) Crossley, A.; Harvey, F. J.; Cape, J. N.; Guillevic, C.; Binnie, J.; Wilson, D. B.; Fowler, D. Proceedings of the 1st International Conference on Fog and Fog Collection; Schememauer, R. S., Bridgeman, H., Eds.; IDRC, Ottawa, 1998. ISBN 0-9683887-0-1.

(10) Crossley, A.; Wilson, D. B.; Milne, R. Environ. Pollut. 1992, 75, 81-87.

(11) Beswick, K. M.; Hargreaves, K.; Gallagher, M. W.; Choularton, T. W.; Fowler, D. Q. J. R. Meteorol. Soc. 1991, 117, 623-646.

(12) Plumacher, J.; Renner, I. Fresenius J. Anal. Chem. 1993, 347, $129-135$

(13) Reimann, S.; Grob, K.; Frank, H. Environ. Sci. Technol. 1996, 30, 2340-2344.

(14) Berg, M.; Muller, S. R.; Muhlemann, J.; Wiedmer, A.; Schwarzenbach, R. P. Environ. Sci. Technol. 2000, 34, 2675-2683.

(15) Frank, H.; Renschen, D.; Klein, A.; Scholl, H. J. High. Resolut. Chromatogr. 1995, 18, 83-88.

(16) EuroChlor. Trichloroacetic Acid; EuroChlor, Brussels, 2001,

(17) Pankow, J. F. Atmos. Environ. 1994, 28, 185-188.

(18) Muller, S. R.; Zweifel, H. R.; Kinnison, D.J.;Jacobsen, J. A.; Meier, M. A.; Ulrich, M. M.; Schwarzenbach, R. P. Environ. Toxicol. Chem. 1996, 15, 1470-1478.

(19) Hoekstra, E. J.; Deleer, E. W. B.; Brinkman, U. A. T. Chemosphere 1999, 38, 551-563.

(20) Franklin, J. Toxicol. Environ. Chem. 1994, 46, 169-182.

(21) Talukdar, R. K.; Mellouki, A.; Burkholder, J. B.; Gilles, M. K.; Le Bras, G.; Ravishankara, A. R. J. Phys. Chem. A 2001, 105, 51885196.

Received for review December 11, 2002. Revised manuscript received March 18, 2003. Accepted April 2, 2003.

ES026411S 